\title{
PATIENTS WITH CARDIAC VALVE PROSTHESIS: SUBSEQUENT ANAESTHETIC MANAGEMENT FOR NON-CARDIAC SURGICAL PROCEDURES *
}

\author{
Jean-Guy MaIllé, M.D., $\nmid$ Ihor Dyrda, M.D., \\ Bernhard Patement, M.D., † AND Marcel Boulanger, m.D. $†$
}

IN RECENT YEARS, cardiac surgery has created a new category of patients: individuals with prosthetic heart valves. The number of these patients is growing rapidly, and many will require the services of anaesthetists either for surgery or intensive care. This study will review the clinical problems associated with prosthetic valves, and the anaesthetic management of such patients.

The clinical problems in patients with a single prosthesis are fewer but not different from those seen in patients with multiple valves. ${ }^{1}$ For this reason, we will consider all patients with artificial valves as a homogeneous group. Points of interest to anaesthetists will be stressed.

\section{Survival rate}

Recent figures indicate a long-term (more than two years) survival rate of 70 to 75 per cent. ${ }^{2-5}$ Our own ten-year experience with more than 1,000 cases corroborates these figures.

\section{Clinical condition of surviving patients}

Our study disclosed a subjective improvement in 89 per cent of surviving patients. ${ }^{6.7}$ Most of them lead a near-normal life. The measurement of improvement was based on the New York Heart Association Classification.

In 34 per cent of the cases, considered as good results, the functional incapacity decreased by two grades. In another 55 per cent, considered as satisfactory results, the functional incapacity decreased by one grade. The remaining 11 per cent showed no change in their incapacity. The functional improvement to be expected is usually maximal after two years.

Radiological signs of cardiomegaly and pulmonary hypertension fade away progressively over a period of two to five years. ${ }^{8}$ The electrocardiographic signs of left ventricular hypertrophy and strain usually regress over the years but rarely disappear completely. ${ }^{6-9}$

Most patients can resume a mild degree of physical activity three months postoperatively. ${ }^{10}$ Fifty-five per cent tolerate a level of activity that can be considered as normal, six months after surgery.9,11

However, even in cases considered as improved by surgery, some degree of

Presented at the Spring Meeting of the Canadian Anesthetists Society (Quebec Division), 1972.

†Department of Anesthesiology, Montreal Heart Institute.

$\$$ Department of Medicine, Montreal Heart Institute. 
congestive failure may persist. ${ }^{\top}$ This condition will be more frequent and more severe in the 11 per cent who are not improved by surgery. The same applies to arrythmias.

Atrial fibrillation, quite common with mitral disease, may persist after surgery. Sixty-seven per cent of our patients with mitral disease had atrial fibrillation. The incidence of this arrythmia was reduced to 31 per cent after valve replacement. ${ }^{7}$

It is important for anaesthetists to realize that patients with prosthetic valves often take a variety of drugs (diuretics, digitalis, anticoagulants, etc.) and are usually on a low sodium diet. ${ }^{8,9}$ Such regimen may modify the patient's response to anaesthetics.

A ten-year follow-up has shown that 80 per cent of the surviving patients will not present any serious complication. The remaining 20 per cent will suffer one or more major complications directly related to the prosthesis.

\section{Complications}

\section{Decreased cardiac output}

Most prosthetic heart valves produce a slight degree of stenosis. ${ }^{12-14}$ This condition is well tolerated unless there is tachycardia. However, the cardiac output will be reduced severely by:

(a) dysfunction of the prosthesis, secondary to thrombi, disinsertion, obstruction by fibrous growth, etc. ${ }^{15,16,17,35}$

(b) dysfunction of the myocardium secondary to diffuse heart muscle disease or coronary insufficiency. ${ }^{\mathbf{1 2 , 1 8 , 3 5}}$

\section{Thrombo-embolic accidents}

This is the most frequent complication of valvular replacement. ${ }^{19}$ The most common and dangerous sites of embolic accidents involve the cerebral and coronary arteries. ${ }^{20}$ Thrombus formation upon the valve itself may interfere with its function. ${ }^{21,22,34}$ The mitral valve, which lies in a low pressure system, is a more likely site of thrombus formation than the aortic valve. Surprisingly, in our experience the incidence of thrombi does not increase with atrial fibrillation. ${ }^{23}$ Clothcovered cages, ${ }^{24,25}$ better surgical techniques ${ }^{5}$ and the use of haemodilution ${ }^{4}$ with the extra-corporeal circulation contribute to a significant decrease of thrombus formation. Thus patients with the newer aortic valve prosthesis do not need anticoagulant therapy.

However, in patients with mitral prostheses, the best protection is still provided by anticoagulants. ${ }^{40}$ It has been shown, indeed, that patients with a constantly well controlled prothrombin time (below 30 per cent) have four times fewer embolic accidents. ${ }^{9}$ On the other hand, good control is difficult to attain and carries its own morbidity. ${ }^{19,20,26}$

\section{Haemolysis}

High flow and turbulence cause mechanical trauma to the red cells and produce haemolysis. ${ }^{23,27}$ Infra-clinical, that is compensated, haemolysis is very frequent, varying from 67 per cent ${ }^{27}$ to 92 per cent. ${ }^{5}$ The existence of haemolysis can be 
shown by red cell survival studies, bilirubin measurements, reticulocyte count, serum iron determination, etc. ${ }^{27,28}$ In 5 per cent of the patients, the haemolysis is severe and does not respond to intensive iron therapy. These patients with haemolytic anaemia may require blood transfusions. The replacement of a haemolyzing valve may be necessary and sometimes beneficial. It is worthwhile to remember that the cloth-covered valve reduces the incidence of thrombus formation but increases the incidence and severity of haemolysis.

\section{Coronary insufficiency}

This complication may be related either to coronary emboli or to obstruction of the coronary ostia by a large aortic prosthesis or by fibrous tissue growth ${ }^{10}$ secondary to jet lesions.

\section{Endocarditis}

Infection at the site of the artificial valve occurs in 1 to 3 per cent of cases and is disastrous. ${ }^{1,2,30}$ A fatal issue is indeed reported in 50 to 90 per cent of such cases. ${ }^{9,10}$ This was the fate of 12 out of 23 patients in our hospital.

Dangerous situations potentially leading to such mishaps include surgery (decreased resistance, trauma, punctures, mucous lacerations by intubation or urethral catheter), dental infections, upper respiratory tract infections, urological or post-partum infections, etc.

\section{Arrythmias}

Besides the arrythmias unrelated to surgery, new ones may result from myocardial irritation by a prosthetic valve or may follow surgical trauma to the A.V. conductive tissue ${ }^{9,20}$ and coronary insufficiency induced by surgery. ${ }^{31}$

\section{Pre-operative Assessment and Preparation For Anaesthesia}

These are high-risk patients and require careful assessment. The anaesthetist should gather precise information, especially on the following points:

\section{Cardiac function}

(a) The patient should be carefully examined for any sign of heart failure.

(b) Valvular incompetence should be suspected in the presence of unexpected heart murmur, cardiomegaly and signs of severe haemolysis.

(c) Arrythmias and their influence on cardiac output should be noted.

(d) In emergency situations, a good clinical examination will usually yield enough information to assess the patient's cardiac function, even in the absence of highly sophisticated tools. ${ }^{31-33}$

\section{Pulmonary function}

Radiological evidence of pulmonary hypertension ${ }^{13}$ is looked for, since patients with this complication are more prone to pulmonary oedema, atelectasis and pulmonary infections. ${ }^{3}$ Moreover, sequelae of thoracotomy (adhesion, pachypleuritis and loss of tissue elasticity) contribute to a higher incidence of pulmonary complications. 


\section{Neurological status}

A brief neurological evaluation is necessary as a point of reference in case of cerebral accident during or after operation.

\section{Medication}

(a) Anticoagulants:

Most of these patients are on anticoagulant therapy. ${ }^{40}$ Enhancement of action of these agents is known to occur with salicylates, phenylbutazone, digitalis, antibiotics. On the other hand, barbiturates decrease anticoagulant activity through enzymatic induction. ${ }^{41}$ During the first year after valve replacement, especially if it is a mitral or a tricuspid valve, anticoagulants should not be stopped before surgery; most surgical procedures are possible even on this therapy. However, in some instances where haemostasis is difficult or bleeding can be disastrous (v.g. multiple dental extractions, vascular surgery, neuro-surgery, etc.) anticoagulants should be withdrawn 24 hours before operation. Phytonadione (Vitamin $\mathrm{K}_{1}$ ) will be administered to bring the prothrombin time to about 50 to 60 per cent, a level sufficient for haemostasis and allowing a rapid return to full anticoagulant therapy post-operatively.

Anaesthetists should be reminded of the danger of peridural anaesthesia in the patient receiving anticoagulant therapy. A peridural haematoma is a very sad event, indeed. ${ }^{38,42,43,54,55}$

(b) Digitalis

Although there is no consensus on this issue, it is our feeling that, in the absence of cardiac failure, digitalis should be stopped 24 to 48 hours pre-operatively. Interpretation and treatment of arrythmias are simplified if digitalis toxicity can be ruled out as a possible cause. ${ }^{44}$

Digitalis toxicity is enhanced by hypoxia and hypokalaemia. Halothane and methoxyflurane increase digitalis tolerance. Barbiturates do not seem to modify this tolerance. ${ }^{58}$

(c) Diuretics

Anaesthetists should be aware that regular use of these agents often results in moderate dehydration, hypovolaemia and electrolyte imbalance, particularly for potassium and magnesium..$^{57,58}$

(d) Beta-blockers (v.g. propranolol)

These agents are often used in patients suffering from angina pectoris, arrythmias and high blood pressure. They are often beneficial by reducing heart work and oxygen requirements but they cause a depression of myocardial contractility and a decrease in cardiac output. These drugs should be stopped at least 48 hours pre-operatively; for elective surgery, it is recommended to withhold the drugs a week before operation. One should bear in mind that beta stimulating drugs (Isoproterenol, Noradrenaline, etc.) may be less effective in the presence of beta-blockers. It has been suggested that Glucagon, acting by other mechanisms, may be useful in such cases. ${ }^{59}$ This assertion needs further substantiation. Another effect of propranolol is to potentiate the effect of curare. ${ }^{38}$

\section{Serum potassium}

Many patients on diuretic therapy will have low blood potassium: this deficit 
should always be corrected before operation. It is well established that hypokalaemia can lead to serious ventricular arrythmias, especially in digitalized patients. ${ }^{44,45}$ The occurrence of ventricular arrythmias in a digitalized patient demands the immediate control of serum potassium level. It must be stressed that plasma potassium determinations show the extra-cellular concentration and do not necessarily reflect the intra-cellular situation.

\section{Haemoglobin}

Anaemias, haemolytic or otherwise, may be present and may require correction pre-operatively. Bearing in mind the dangers of overloading the circulation, packed cells are often preferable to whole blood for transfusion.

\section{Infectious foci (teeth, bladder, vagina, etc.)}

These must be detected and eliminated as a potential source of bacteraemia which may result in a disastrous endocarditis. ${ }^{46}$

\section{Preventive antibiotic therapy}

Antibiotic protection is mandatory, and should be started at least 24 hours preoperatively and will include gram-positive (cloxacilline, methicilline, cephalosporine) and gram-negative (ampicilline, cephalosporine) active antibiotics. ${ }^{23}$ The therapy must be carried on during the operation and maintained for five days post-operatively, or longer if indicated. This therapy is also very important in minor surgery (tooth extraction, fracture reduction, etc.).

\section{Premedication}

The psychological preparation is as important $\mathrm{t}^{47}$ as the premedicament itself. These patients are often very anxious: they usually know more about their disease than the average patient. This is the right place for a warm reassuring relationship.

Intramuscular barbiturates with scopolamine are usually well tolerated and provide sufficient sedation without undue depression. ${ }^{48}$ As a general rule, we include scopolamine for its amnesic effect and its smoother action on cardiac rhythm.

\section{Anaesthetic Management}

\section{General considerations}

(a) These patients have less cardiovascular stability and less tolerance to depressive agents.

(b) Obsessive aseptic technique is observed in placing intravenous infusions, catheters, cannulae, tubes, etc. This applies for surgery too.

(c) Monitoring: pulse rate, arterial pressure and continuous EKG oscilloscope monitoring is essential and is considered as a bare minimum.

More sophisticated and precise monitoring is indicated when the operation is extensive in importance, duration and consequences; direct intraarterial pressure measurement, central venous pressure, serial $\mathrm{pH}$ measurements, diuresis, temperature, improve the safety of anaesthesia. 


\section{Induction}

Thiopentone is not contraindicated. As a matter of fact, it is probably the most frequently used induction agent, but the dosage should be kept low. ${ }^{60}$

Induction can also be conducted with intravenous narcotics. ${ }^{49,50}$ Morphine is becoming very popular ( 1.0 to $1.5 \mathrm{mg} / \mathrm{kg}$ ) ${ }^{51} \mathrm{In}$ such cases, thiopentone is added in very small doses ( 50 to $100 \mathrm{mg}$ ).

Neuroleptics, narcotic mixture and diazepam ${ }^{60}$ have all been used safely. Whatever is used, the anaesthetist should avoid undue depression from overdose; on the other hand, a stormy induction from too little is just as bad. ${ }^{48}$

Despite its tendency to induce arrythmias, succinylcholine is still commonly used for intubation..$^{39,48}$ The superiority of non-depolarizing agents, including pancuronium, has yet to be established. ${ }^{61}$

\section{Maintenance}

Any important reduction of cardiac output will favour metabolic acidosis and thrombus formation among other things. For this reason, agents known to depress the myocardial fiber or to dilate the peripheral vascular bed are best avoided. Halogenated anaesthetics do not appear to be the agents of choice. ${ }^{52,53}$ Our experience with balanced anaesthesia using morphine and nitrous oxide has been most satisfactory in cardiac patients at large.

Moreover, severe bradycardia and tachycardia, through different mechanisms, will reduce the cardiac output and should be prevented.

The use of atropine in cardiac patients has always been somewhat controversial: excessive tachycardia and various other arrythmias following intravenous atropine have been frequently reported and are well documented. Massumi et al. have recently reported the occurrence of ventricular fibrillation and tachycardia following its use. ${ }^{62}$

During anaesthesia, bradycardia from vagal activity is sufficiently prevented by the judicious use of gallamine as to make further correction rarely indicated. Pancuronium appears to be equally promising in this respect. Curare should be used cautiously, bearing in mind its potential hypotensive effect. On the other hand, this agent may prove useful in presence of hypertension.

These patients should receive at least 40 per cent oxygen in the inspired gases. Ventilation should aim at maintaining a near normal $\mathbf{P c o}_{2}$. Acidosis depresses myocardial contractility, may lead to arrythmias, causes peripheral vasodilatation and a poor response to catecholamines. ${ }^{63}$ Hyperventilation can also lead to arrythmias by lowering the serum potassium, and causes vasoconstriction.

Precise assessment of fluid requirements is essential. These patients are as intolerant to hypovolaemia as they are sensitive to fluid overload. Central venous pressure and monitoring of urinary output are useful guides for adequate therapy.

The reversal of curarization is rarely attempted at the end of surgery to avoid atropine-neostigmine induced arrythmias. The ventilation is routinely supported in the immediate post-operative period under proper sedation. 
Post-operative Care

The same monitoring (C.V.P., cardiac rhythm, B.P., urinary output, etc.) must be carried on through the recovery period until return to full cardiovascular stability. ${ }^{4}$

The temperature is closely watched. Blood cultures are ordered at the slightest sign of infection. Any septicaemia must be considered as an endocarditis and treated as such with massive doses of antibiotics. It is wise to transfer the patient to a specialized unit at any sign of endocarditis. An intensive chest therapy program will help to prevent pulmonary complications. The pulmonary status is controlled daily by clinical observation and chest X-ray.

Cannulae, catheters, tubes, etc. must be removed as soon as possible, since they are all possible points of entry for infections.

Digitalis and diuretic therapy are reintroduced usually 24 hours post-operatively; anticoagulants can usually safely be started three to four days after surgery.

\section{Conclusion}

Patients with prosthetic valves are more sensitive than others to changes in their biologic parameters (blood volume, $\mathrm{pH}$, electrolytes, etc.). They require a careful pre-operative assessment. The most important part of this assessment is a sound clinical evaluation. The haemodynamic effects of the prosthesis and the potential complications associated with it must be understood. The medication of these patients should be reviewed keeping in mind the anaesthetic and surgical implications of these drugs.

The anaesthetic management should be focused on avoidance of cardiovascular depression. "Failsafe" attention is mandatory since there is less room for error.

\section{SUMMARY}

Over 75 per cent of patients with heart valve prostheses will survive two years or more. This paper analyzes their general clinical condition, pointing out the complications that may eventually threaten them.

These patients are likely to appear in the unspecialized anaesthetic practice and represent a new challenge for the anaesthetist, who must be familiar with their management. The pre-operative assessment and preparation, the pre-anaesthetic precautions and post-operative care have been reviewed in this paper.

\section{RÉSUMÉ}

Au delà de 75 pour-cent des malades porteurs de valves cardiaques artificielles survivent deux ans et plus. Ce travail analyse leur état clinique en général et les complications qui éventuellement peuvent les menacer.

Ces malades, qui présentent un défi particulier, peuvent apparaître dans la pratique courante de tout anesthésiste. A cet effet, nous décrivons l'approche de tels malades au plan de l'evaluation et de la préparation pré-opératoire, de la conduite de l'anesthésie et des suites opératoires. 


\section{REFERENCES}

1. Duvoisin, G.E., Wallace, R.B., Ellis, F.H. Jr., Anderson, M.W., \& McGoon, D.C. Late results of cardiac-valve replacement. Circulation 37-38: II-75 (1968).

2. Reed, W. \& Dunn, M. Long-term follow-up of patients with aortic valve replacement. Circulation 41-42: II-44 (1970).

3. Najaft, H., Dye, W.S., Javm, H., Hunter, J.A., Ostermiller, W.E. Jr., \& Julian, O.C. Mitral valve replacement. Amer. J. Cardiol. 24: 386 (1969).

4. Fishman, N.H., Hutchinson, J.C., Massengale, M.M., \& Roe, B.B. Follow-up evaluation of 100 consecutive mitral prosthesis implants. Arch. Surg. 97: 691 (1968).

5. Herr, R.H., Starr, A., Pierie, W.R., Wood, J.A., \& Bigelow, J.C. Aortic valve replacement. Ann. Thorac. Surg. 6: 199 (1968).

6. Aerichide, N., Boucher, R., Campeau, L., Grondin, P., Lepage, G., \& David, P. Evaluation des remplacements valvulaires aortiques isolés. Etude de 200 cas. Un Méd. Can. 101: 453 (1972).

7. Aerichide, N., Boucher, R., Campeau, L., Lepage, G., Grondin, P., \& David, P. Evaluation des remplacements valvulaires mitraux isolés. Etude de 300 cas. Submitted for publication.

8. Penther, P., Bensaim, J., Sozuter, Y., Maurice, P., \& Lenègre, J. Pronostic éloigné de la valve de Starr mitrale et aortique. Arch. Mal. Cour 5: 679 (1969).

9. Bensaim, J., Penther, P., Grand, A., Coblence, B., Maurice, P., \& Lenègre, J. Résultats éloignés du traitement chirurgical de l'insuffisance aortique pure par prothèse de StarrEdwards. Arch. Mal. Couur 3: 386 (1968).

10. Soulie, P., Fouchard, J., Valty, J., Heulin, A., Caramanian, M., \& Degeorges, M. Résultats éloignés de la correction de 202 cas de valvulopathies aortiques par prothèse de Starr-Edwards. Arch. Mal. Cour 12: 1688 (1970).

11. Beall, A.C. Jr., Bloodwell, R.D., Bricker, D.L., Okies, J.E., Cooley, D.A., \& Debakey, M.E. Prosthetic replacement of cardiac valves. Amer. J. Cardiol. 23: 250 (1969).

12. Vogel, J.H.K., Paton, B.C., Overy, H.R., \& Blount, S.G. JR. Abnormal hemodynamic function after disc mitral valve replacement. Circulation 39-40: I-141 (1969).

13. Reid, J.A., Stevens, T.W., Sigwart, U., Fulweber, R.C., \& Alexander, J.K. Hemodynamic evaluation of the Beall mitral valve prosthesis. Circulation 45: (suppl. I) (1972).

14. Glancy, L., O’Brien, P., Reis, R.L., Epstein, S.E., \& Morrow, A.G. Hemodynamic studies in patients with $2 \mathrm{M}$ and $3 \mathrm{M}$ Starr-Edwards prostheses; evidence of obstruction to left atrial emptying. Circulation 39-40: I-113 (1969).

15. Chin, H.P., Harrison, E.C., Blankenhorn, D.H., \& Moacanin, J. Lipids in silicone rubber valve prostheses after human implantation. Circulation 43-44: I-51 (1971).

16. Hutchison, J.D. \& Paton, B.C. Scanning electron microscopy for examination of prosthetic valve balls. Circulation 41-42: II-10 (1970).

17. Horsley, H.T. Jr., Rappoport, W.J., Vigoda, P.S., \& Vogel, J.H.K. Fatal malfunction of Edwards low-profile mitral valves. Circulation 41-42: II-39 (1970).

18. Linhart, J.W., Barold, S.S., Hildner, F.J., Samet, P., Piccinini, J.C., Marsten, J.L., \& GreENBERG, J.J. Clinical and hemodynamic findings following replacement of the mitral valve with a Beall valve prosthesis (dacron velour-covered teflon-disc valve). Circulation 39-40: I-127 (1969).

19. Freidi, B., Aerichide, N., Grondin, P., \& Campeau, L. Thromboembolic complications of heart valve prostheses. Amer. Heart J. $81: 702$ ( 1971).

20. Reed, G.E., Crauss, R.H., Tice, D.A., \& Acinapura, A.J. Five-year experience with Magovern aortic prostheses. Circulation 43-44: I-73 ( 1971 ).

21. Vander Veer, J.B. Jr., Rhyneer, G.S., Hodam, R.P., \& Kloster, F.E. Obstruction of tricuspid ball-valve prostheses. Circulation 43-44: I-62 (1971).

22. Editorial: Platelet thrombosis on prosthetic valves. New Eng. J. Med. 279: 603 (1968).

23 Herr, R., Starr, A., McCord, C.W., \& Wood, J.A. Special problems following valve replacement. Ann. Thorac. Surg., 1: 403 (1965).

24. Hodam, R., Starr, A., Raible, D., \& Griswold, H. Totally cloth-covered prostheses. A review of two years' clinical experience. Circulation 41-42: II-23 (1970).

25. Kloster, F.E., Herr, R.H., Starr, A., \& Griswold, H.E. Hemodynamic evaluation of a cloth-covered Starr-Edwards valve prosthesis. Circulation 39-40: I-119 (1969).

26. Gadboys, H.L., Litwak, R.S., Niemetz, J., \& Wisch, N. Anticoagulants prevent emboli in valve implant. Mod. Med. 23: 57 (1968). 
27. Crexellis, C., Aerichide, N., Bonny, Y., Lepage, G., \& Campeau, L. Factors influencing hemolysis in valve prosthesis. Amer. Heart J. 84: 161 (1972).

28. WALSh, J.R., StaRr, A., \& Ritzman, L.W. Intravascular hemolysis in patients with prosthetic valves and valvular heart disease. Circulation 39-40: I-135 (1969).

29. Rodgers, B.M. \& SABISton, D.C. JR. Hemolytic anemia following prosthetic valve replacement. Circulation 39-40: I-155 (1969).

30. Dyrda, I., Choquet, Y., Campeau, L., \& David, P. L'endocardite bactérienne. Ann. Cardiol. Angéiol. 6: 717 (1971).

31. Davies, L.G. Valve replacement. Brit. Heart J. 32: 723 (1970).

32. Johnson, M.L., Paton, B.C., \& Holmes, J.H. Ultrasonic evaluation of prosthetic valve motion. Circulation 41-42: II-3 (1970).

33. Mercer, E.M., McCallister, B.D., Givlliani, E.R., \& Zitnik, R.S. Aortic opening to closing ratio on phonocardiograms of patients with Starr-Edwards aortic valve prostheses. Mayo Clin. Proc. 47: 41 (1972).

34. Hylen, J.C. Durability of prosthetic heart valves. Amer. Heart J. $81: 299$ (1971).

35. Sutron, G.C. \& Wright, J.E.C. Major detachment of aortic prosthetic valves. Brit. Heart J. 32: $337(1970)$.

36. Sullivan, J.M., Harken, D.E., \& Gorlin, R. Pharmacologic control of thromboembolic complications of cardiac-valve replacement. New Eng. J. Med. 284: 1391 (1971).

37. Sullivan, J.M., Harken, D.E., \& Gorlin, R. Effect of dipyridamole on the incidence of arterial emboli after cardiac valve replacement. Circulation 39-40: I-149 (1969).

38. Harrah, M.D., Way, W.L., \& KalzUNG, B.G. The interaction of d. tubocurarine with antiarrhythmic drugs. Anesthesiology 33: 406 (1970).

39. Wylie, W.D. \& Churchill-Davidson, H.C. A practice of anesthesia. Year Book Medical Publishers, 3rd edition, Chicago (1972).

40. Winters, T.Q. et al. Current status of Starr-Edwards cloth-covered prosthetic cardiac valves. Circulation 45: I-14 (1972).

41. Roch-Weser, J. \& Sellers, E.M. Drug interaction with coumarin anticoagulants (Part II). New Eng. J. Med. 285: 547 (1971).

42. LUND, P.C. Indications and contraindications for peridural anesthesia. Intern. Anesth. Clin. 2: 592 ( 1964).

43. Lamarche, Y. Personal communication.

44. Harrison, D.C., Kerber, R.E., \& Alderman, E.L. Pharmacodynamics and clinical use of cardiovascular drugs after cardiac surgery. Amer. J. Cardiol. 26: 385 (1970).

45. McGoon, D.C. \& Pluth, J.R. Postoperative care of the open-heart patient. Cardiovasc. Surg. 1: 33 (chapter 2), edited by Burford, T.H. and Ferguson, T.B., C.V. Mosby Co., St. Louis (1969).

46. Sandie, M.A., Johnson, W.D. Jr., Hooks, E.W., \& KaYe, D. Sustained bacteriemia in patients with prosthetic cardiac valves. New Eng. J. Med. 286: 1067 (1972).

47. KornfELD, D.S. Psychiatric aspects of patient care in the operating suite and special areas. Anesthesiology 31:166 (1969).

48. Tarhan, S. \& Moffitt, E.A. Anesthesia and supportive care during and after cardiac surgery. Ann. Thor. Surg., current review 11: 64 (1971).

49. Hasbrouck, J.D. Morphine anesthesia for open-heart surgery. Ann. Thor. Surg. 10: 364 (1970).

50. KenM, J.C., MaCK, F.E., \& SChLobohn, R.M. The hemodynamic changes of large doses of morphine in humans. Abstracts of scientific paper, A.S.A. 1970 Annual Meeting, New York.

51. Lowenstein, E., Hallowell, P., Levine, F.H., Daggett, W.M., Austen, G.N., \& Laver, M.B. Cardiovascular response to large doses of intravenous morphine in man. New Eng. J. Med. 281: 1389 (1969).

52. LundburG, R.O., Shahbudin, H.R., \& Swan, H.I.C. Halothane administration and left ventricular function in man. Anesth. Analg. 46: 377 (1967).

53. Restall, J.C., Milde, J.H., \& Theye, R.A. Circulatory indexes of methoxyflurane, halothane and ether anesthesia. Anesth. Analg. 45: 330 (1966).

54. Butrer, A.B. \& Green, C.D. Hematoma following epidural anesthesia. Can. Anesth. Soc. J. 17: $635(1970)$.

55. Bonica, J.J. Comment. Surv. Anesthesiol. 16: 60 (1972).

56. Morrow, D.H., Haley, J.V., \& Logic, J.R. Anesthesia and digitalis VII. The effect of pentobarbital, halothane and methoxyflurane on the A.V. conduction and inotropic response to Ouabain. Anesth. Analg. 51: 430 (1972). 
57. Garcia, D.A. \& YendT, E.R. The effect of probenecid and thiazides and their combination on the urinary excretion of electrolytes and on acid-base equilibrium. Can. Med. Ass. J. 103: $473(1970)$.

58. Duarte, C.G. Effects of ethacrynic acid and furosemide on urinary calcium phosphate and magnesium. Metabolism 17: 867 (1968).

59. Ivankovic, A.D. Anesthetic management problems posed by therapeutic advances: II. Digitalis and Glucagon. Anesth. Analg, current researches 51: 607 (1972).

60. KNAPP, R.B. \& Dubow, H. Comparison of Diazepam with Thiopental as an induction agent in cardiopulmonary disease. Anesth. Analg. 49: 722 (1970).

61. Harrison, G.A. The cardiovascular effects and some relaxant properties of four relaxants in patients about to undergo cardiac surgery. Brit. J. Anesth. 44: 485 ( 1972 ).

62. Massumi, R.A., Mason, D.T., Amsterdam, E.A., DeMaria, A., Miller, R.R., Scheinman, M.M., \& ZELIS, R. Ventricular fibrillation and tachycardia after intravenous atropine for treatment of bradycardias. New Eng. J. Med. 287: 336 (1972).

63. Scurr, C. 3 Feldman, S. Scientific Foundations of Anesthesia, F.A. Davis Co., p. 298, Philadelphia (1970). 